\title{
MERCOSUL: CRISE DE CRESCIMENTO OU CRISE TERMINAL?
}

Sonia de Camargo

Neste fim de 2005 (quando o presente artigo foi escrito), dúvidas sobre a funcionalidade do Mercosul, ou melhor, sobre sua capacidade de gerar benefícios econômicos e políticos para seus Estados-membros, individualmente, e para a sub-região como um todo, tendem a se acentuar no meio dos analistas e de certos setores da sociedade, apesar de que o discurso pró-Mercosul continue com força no âmbito de seus governos. Na realidade, essas dúvidas têm a ver com o fato de que o Mercosul vem encontrando, desde fins dos anos 1990, dificuldades crescentes para avançar na direção do que se havia proposto, o de constituir um mercado comum com capacidade para se irradiar por todo o continente sul-americano.

É claro que essas dificuldades não podem ser imputadas exclusivamente a inconsistências internas ou erros de percurso cometidos pelo Mercosul em seu processo de integração. Em sua avaliação não se pode deixar de levar em conta a conjuntura internacional e a estrutura global da ordem mundial em cujo contexto foi criado e que o acompanha em sua trajetória posterior. Isso aponta para o fato de que, 
para países de menor desenvolvimento relativo, os chamados países emergentes, as exigências de competividade de suas economias geradas pela liberalização dos mercados e pela internacionalização dos capitais tornaram mais pesadas as assimetrias e desigualdades dentro e entre os Estados e sociedades da região, gerando desconfianças e conflitos em seu relacionamento.

Isso fica claro se nos voltarmos especificamente para o Mercosul em que o Brasil, ao concentrar três quartos do Produto Interno Bruto (PIB) da união platina e responder por um terço das compras e vendas externas do Uruguai e do Paraguai, constitui um foco de atrito que exige políticas compensatórias que preservem o objetivo do Tratado de Assunção, o de constituir um mercado comum sub-regional. Contudo, se olharmos por outro ângulo, vemos que, apesar de que o caminho iniciado pelo Mercosul é de difícil realização, sua legitimidade tem crescido em razão do refluxo 58 da legitimidade do discurso dominante que prega a diluição de fronteiras e prevê o declínio irreversível dos Estados nacionais. Como decorrência, o que vemos é que algumas iniciativas que se apresentavam promissoras para a América Latina, como a dolarização de suas economias - que chegou a ser aplicada em alguns países como o Equador -, assim como a constituição de uma Área de Livre Comércio das Américas (Alca), proposta pelos Estados Unidos, perderam visibilidade ou passaram a ser questionadas por países da região, entre os quais o Brasil. O próprio acordo Mercosul/União Européia, que gerava menos desconfiança, amorteceu o passo. Com isso, além do Mercosul, a própria proposta de integração de todo o continente sul-americano começa a ser vista como um projeto no qual vale a pena apostar (Batista Junior, 2005).

Isso não invalida o fato de que o Mercosul tem problemas graves que precisam ser solucionados. Atingido pelas crises internas de seus Estados-membros e pelos conflitos 
comerciais crescentes entre eles, é necessário que o projeto seja repensado, especialmente no que se refere à sua estrutura institucional e a seus objetivos e planos de ação de curto e longo prazo, levando-se em conta que a integração comercial entre seus países já é uma realidade, ainda que o objetivo de constituir um mercado comum nos próximos dez anos apareça como inviável, sobretudo diante da decisão de incorporar novos membros, Chile, Bolívia, Peru, Colômbia, Equador, Venezuela ${ }^{1}$ (Giambiagi e Barenboim, 2005).

Situando, assim, o Mercosul dentro do contexto geral da ordem mundial em que se desenvolve e como centro dos acordos de livre comércio com os outros países sul-americanos, proponho-me a examinar neste artigo as principais razões internas e externas que estão na base das dificuldades que obstaculizam seu avanço, isto é, as que são geradas no interior de cada um dos países que compõem o bloco e as que surgem na dinâmica das relações entre eles e deles com outros Estados da região. Proponho-me, também, examinar as diferentes reações que essas dificuldades produzem no interior do próprio bloco, isto é, nas sociedades que o integram e no discurso daqueles que têm como função - governos e lideranças políticas e empresariais - defender os interesses individuais de cada um dos seus Estados-membros levando em conta, simultaneamente, os interesses coletivos do conjunto.

Quando nos referimos ao Mercosul, um primeiro ponto que cabe salientar é que Brasil e Argentina, dadas suas dimensão e importância no contexto sub-regional da Bacia do Prata e no resto da região sul-americana, marcam o ritmo em que o projeto Mercosul caminha e a direção que se

1. Os países acima citados foram incorporados ao Mercosul como membros associados ao longo de 2004. Em dezembro de 2005, na reunião de cúpula do Mercosul, a Venezuela passou a ser considerada como um "membro em via de adesão", isto é, praticamente como o primeiro novo membro pleno do bloco. 
propõe seguir. A partir dessa premissa ${ }^{2}$, pretendo priorizar, em minha análise, o relacionamento entre esses dois países a partir do fim dos anos 1980, momento em que, depois de quase dois séculos de conflitos gerados pela disputa pelo controle da Bacia do Prata e, posteriormente, pelo início de uma perigosa corrida nuclear, felizmente desarmada no nascedouro, as relações entre Brasil e Argentina, já pacificadas, se voltam para a construção de um projeto de integração entre os quatro países platinos destinado a assegurar o equilíbrio de poder na sub-região.

Com isso se encerra um período em que a disputa pela hegemonia continental cobrira a maior parte da história das relações bilaterais entre Argentina e Brasil e se inicia outro em que a democratização, nos anos 1980, de grande parte dos países sul-americanos, entre os quais a Argentina, Brasil, Bolívia, Uruguai, Peru, e maiores convergências políticas e econômicas entre eles, impulsionam a revisão de 60 algumas hipóteses de conflito e de alguns acordos anteriores de integração sub-regional ${ }^{3}$. Abre-se então um espaço para que novas fórmulas de cooperação bilateral e multilateral pudessem surgir impulsionadas pelas tendências que emergiam, com rapidez inusitada, no plano internacional e mundial, conduzindo os países sul-americanos a ajustarem

2. Essa afirmação tem a ver com fato de que, mesmo que o bloco Mercosul se componha de quatro países, Brasil, Argentina, Uruguai e Paraguai, os dois primeiros concentram 96,2\% de sua população e 97,2\% do PIB. Ver: Roberto Lavagna (1995).

3. O Regime Militar, no Brasil, perdurou de 1964 a 1984, ano em que o país abriu um processo eleitoral para Presidente da República que elegeu, de forma indireta, Tancredo Neves. Sua morte, antes de haver tomado posse, conduz à presidência o Vice-Presidente, José Sarney, que iniciou seu mandato em 1985. No que se refere à Argentina, depois de um intervalo democrático de três anos que interrompe a assim chamada "revolução Argentina", de caráter militar-autoritário, e que trouxe novamente ao poder o peronismo, iniciou em 1976, um novo ciclo de regime militar que se encerrou em 1983 com a eleição direta de Raúl Alfonsin. A partir desse momento, os dois países se aproximaram e assinaram um acordo bilateral de integração, embrião do que seria mais tarde o Mercosul. 
suas políticas econômicas nacionais e regionais aos requerimentos da economia política global, cujas exigências de competividade geravam custos difíceis de serem administrados isoladamente.

Essa avaliação, contudo, não tem o mesmo peso para todos os países da região. No caso brasileiro, especialmente, o país chega aos anos 1980 com um padrão de industrialização mais avançado que os demais, havendo incorporado em sua pauta de exportações, durante os anos 1970, bens semi-manufaturados e alguns bens de capital, ainda que esse "crescimento em marcha forçada", que custara ao país um altíssimo endividamento externo, o obrigara a recorrer ao Fundo Monetário Internacional (Furtado, 1982; Castro e Souza, 1985). No que se refere à Argentina, o caminho se fez em sentido contrário. O modelo econômico posto em prática na segunda metade dos anos 1970, período governado por um novo regime militar, retomou o velho projeto exportador primário da "geração de 1880", em que o eixo principal da acumulação se concentrava no setor agropecuário, no qual o país apresentava, tradicionalmente, vantagens comparativas no mercado mundial. Como fruto dessa política econômica, a matriz produtiva argentina sofreu uma verdadeira transformação, levando este país a um sucateamento dos núcleos dinâmicos de seu setor manufatureiro (Camargo e Vasquez Ocampo, 1988).

Essa era a situação econômica dos dois países que, na segunda metade dos anos 1980, legitimados pelo processo de abertura democrática que ambos estavam vivendo, se propõem a integrar bilateralmente seus mercados como uma alternativa aos mercados dos países centrais que tendiam a se fechar. Em 1986 é constituído o Programa de Integração e Cooperação Bilateral Argentina-Brasil (Picab), no marco do qual são assinados os primeiros Protocolos num total de 23 ao longo dos anos 1986-1988, dentre os quais o setor mais dinâmico foi o de bens de capital, essencial para 
a modernização e desenvolvimento científico-tecnológico de seu parque industrial.

Seguiu-se a criação de vários mecanismos de cooperação e, em 1988, é assinado o Tratado de Integração, Cooperação e Desenvolvimento e, dois anos depois, a Ata de Buenos Aires, por meio da qual se constituiu o Grupo Mercado Comum, de natureza binacional (Camargo, 1989). As negociações prosseguiram, já incluindo o Uruguai e o Paraguai, e em 26 de março de 1991 é assinado o Tratado de Assunção mediante o qual fica constituído o Mercado Comum do Sul, oficialmente chamado de Mercosul. Com a assinatura do Protocolo de Ouro Preto, em 1994, definem-se os contornos da União Aduaneira, dando-se a largada para o estabelecimento da Tarifa Externa Comum (TEC), e se confere personalidade jurídica internacional ao Mercosul (Medeiros, 2000).

Cabe lembrar que o acordo bilateral Argentina-Brasil era de natureza essencialmente desenvolvimentista, em 62 que a idéia de preferências comerciais e de promoção de complementaridades intra-setoriais se confundiam com a própria idéia de integração. Esse modelo, contudo, não se reproduzirá no Mercosul, cujas políticas econômicas passaram a se voltar, prioritariamente, para uma melhor adequação às exigências de competividade impostas pelos processos de liberalização dos mercados e de sua integração global, o que revestiu o acordo de um caráter essencialmente comercialista.

Na conjuntura atual do Mercosul, dada sua relativa estagnação, já se questiona a prioridade quase absoluta dada à dimensão comercial adotada ao longo de seu caminho, pondo-se na mesa o tema da necessidade de uma correção de rota, no sentido de, além de voltar a priorizar a integração produtiva entre as economias do bloco, como fora a proposta inicial entre Argentina e Brasil, avançar na construção de uma nova institucionalidade capaz de suprir as distorções trazidas pelo mercado. 


\section{Mercosul na conjuntura dos anos 1990}

Gostaria de lembrar que, durante seus primeiros dez anos aproximadamente, o Mercosul, desde sua concepção e estruturação original, apesar de suas carências nos aspectos institucionais e sociais e de suas dificuldades em implementar uma União Aduaneira inscrita em seus documentos fundadores, ainda era portador de uma carga significativa de otimismo e de esperança. Essa percepção positiva do processo vinha desde as origens do bloco, quando a integração regional de países em desenvolvimento se apresentava como a melhor estratégia para vencer os desafios trazidos pela globalização econômico-financeira que, com sua exigência de competitividade na esfera mundial e com seus atores e sistemas crescentemente internacionalizados e transnacionalizados, conduziam os Estados emergentes a tentar ampliar a escala de sua atividade produtiva e a reforçar as formas de governança regional.

O projeto Mercosul, porém, não foi pensado apenas como uma reação passiva a uma situação exterior da qual não tinha controle, isto é, não foi criado, unicamente, a partir de uma lógica econômica imposta de fora. O Tratado de Assunção, assinado em 1991 no bojo de um acordo entre Argentina, Brasil, Paraguai e Uruguai, institucionalizou e fez avançar um processo iniciado pela aproximação política entre Argentina e Brasil, em 1985, ocasião em que estes dois países, já democratizados e governados por presidentes civis, Raul Alfonsin e José Sarney, podiam começar a pensar em acordos estratégicos que reforçassem a nova conjuntura de governos democráticos na região e elaborassem projetos conjuntos de desenvolvimento (Camargo, 1989). Esses objetivos, contudo, não eram fáceis de alcançar, tendo sido, em parte, gradualmente abandonados no curso do processo, apesar de que o ponto de chegada previsto, a constituição de um mercado comum, parecia inalterado até bem pouco tempo atrás. 
No decorrer dos anos 1990, o Mercosul, recém-criado, conviveu com as crises econômico-financeiras de seus países membros, crises derivadas da adoção de modelos de estabilização macroeconômica e de ajustamento estrutural às novas condições do comércio global que haviam adotado e de abertura indiscriminada de seus mercados. Mesmo assim, conseguiu eludir suas dificuldades por meio de acordos bilaterais ou arranjos quadrilaterais que lhe permitiram avançar em seus compromissos negociados em conjuntos Sem poder afirmar que tivessem caminhado com a mesma intensidade em todas as dimensões de seu projeto de integração, em termos comerciais os países do Mercosul atingiram taxas significativas de intercâmbio intra-regional e extra-regional e, no que se refere especificamente ao Brasil, o país diversificou sua pauta de exportações em favor de produtos de maior valor agregado ${ }^{4}$.

Paralelamente, em termos políticos, a idéia de demo64 cracia foi reforçada no contexto do Mercosul, uma vez que, transcendendo as fronteiras de cada país-membro, esse princípio foi incluído no Protocolo de Ouro Preto tomando a forma de uma cláusula democrática regional que, lançada pelos governos argentino, brasileiro e uruguaio, tinha como endereço o Paraguai, onde uma crise política de grandes proporções antecipava um golpe de caráter militar ${ }^{5}$. Dessa maneira, apesar dos fatores nega-

4. Em termos de intercâmbio intra-bloco, em 1990, as exportações alcançaram $9 \%$ e as importações 15\%. Em 1998, as exportações subiram para $25 \%$ e as importações para $21 \%$. No que se refere ao Brasil, suas exportações para os demais países do bloco, durante a década de 1990, alcançaram 17\% e suas importações $15 \%$. Quanto à Argentina, os números atingiram 36\% e 25\%, respectivamente, o que indica que, se nos referirmos aos dois maiores países do bloco, o Mercosul tem para a Argentina uma importância maior como mercado exportador do que para o Brasil. Essa importância cresce quando referida ao Uruguai e ao Paraguai (Saha, 2002).

5. A crise política paraguaia teve início com o assassinato do Vice-Presidente Juis Maria Argaña a mando do general Lino Oviedo, aliado do então Presidente Raúl 
tivos já mencionados, o avanço comercial e político alcançado nos anos 1990 permitia acreditar na possibilidade de que, por meio do Mercosul, seria possível a criação de um espaço coeso, integrado, economicamente e politicamente, no Cone Sul.

$\mathrm{Na}$ realidade, se examinarmos com mais detalhes esse período, especialmente no que se refere à Argentina e ao Brasil, vemos que, em termos econômicos, deu-se uma convergência entre os governos de Carlos Menem e Collor de Mello, ambos adotando políticas econômicas de corte neoliberal com forte ajuste estrutural, abertura do mercado e privatização de empresas públicas, paradigma que se expressou, regionalmente, em uma nova concepção de integração, "o regionalismo aberto" ". Nesse contexto, o Mercosul, que iniciara seu caminho por uma integração intra-industrial, que tinha como base a assinatura de protocolos referentes às diferentes atividades produtivas do Brasil e da Argentina, sofreu uma mudança de rumo adotando uma política de liberalização linear e automática no intercâmbio de bens, deixando de lado o aprofundamento de outras estratégias de cooperação, além da comercial, que já começara a apresentar um dinamismo significativo.

Simultaneamente, a política externa dos dois países, além da abertura dos mercados, procurou se voltar, com mais afinco, para os países centrais, o que os levou a cons-

Cubas, crise que ganhou as ruas, pondo, de um lado, estudantes e população em geral e, de outro, grupos paramilitares "oviedistas", em meio a ameaças de golpe militar. Por insistência do Presidente Fernando Henrique Cardoso e dos dois outros governos do Mercosul que queriam evitar que a ordem institucional vigente fosse afetada, o presidente Raúl Cubas renuncia ao cargo, pedindo logo em seguida asilo político no Brasil, depois de haver libertado o general Oviedo, que, confinado no Batalhão de Guarda Presidencial, foge imediatamente para a Argentina. 6. Sobre o tema dos "regionalismos abertos", consultar os documentos da Cepal, especialmente o de 24 de maio de 1996, El Regionalismo Abierto: América Latina y el Caribe en la Economia Internacional. 
truir uma agenda positiva com os Estados Unidos e a descaracterizar o perfil terceiro-mundista de que ambos se revestiam. No caso específico da Argentina, sua opção foi de um alinhamento praticamente total aos Estados Unidos, opção que, apoiando-se na percepção de que a nova ordem internacional pós-Guerra Fria seria definida com base em valores liberais e na liderança norte-americana, poderia representar uma contrapartida aos custos das medidas de ajuste econômico postas em prática internamente (Vaz, 2002).

Já no caso do Brasil, a opção por um relacionamento mais próximo com os Estados Unidos não implicava o abandono da visão universalista da sua política externa ou qualquer forma de retrocesso nas relações com os países do Cone Sul e com a Argentina em particular. Nesse contexto, a estratégia adotada pelo Brasil foi a de uma ação simultânea, com sentido de reforço mútuo, no plano das relações bilaterais, regionais e nos foros multilaterais. Com o afastamento 66 de Fernando Collor de Mello e a ascensão à presidência de Itamar Franco e de seu substituto Fernando Henrique Cardoso, o discurso diplomático reafirmou a condição do Brasil como país em desenvolvimento assim como sua prioridade na consolidação do Mercosul e, paralelamente, sua intenção de criar iniciativas que ampliassem para toda a América do Sul o alcance da integração sub-regional (Vaz, 2002).

\section{Anos de crise}

Chega-se, assim, ao fim dos anos 1990, momento em que o Mercosul começa a evidenciar pontos sérios de estrangulamento que desafiam a continuidade do processo. Um dos pontos de maior impacto foi a crise financeira no Brasil com a decorrente desvalorização do real, em janeiro de 1999, moeda que, desde 1994, mantivera a paridade fixa com o dólar, sistema adotado na Argentina desde 1991. A decisão do governo brasileiro, tomada unilateralmente e sem acordo prévio com os demais parceiros do bloco, rompia com a con- 
vergência anterior entre o sistema de câmbio fixo adotado nos dois países, o que não podia deixar de ter conseqüências sérias para a Argentina, dado seu alto grau de interdependência e de assimetria econômica em relação ao Brasil ${ }^{7}$.

Dessa maneira, em uma conjuntura em que o Brasil desvalorizara em 35\%, aproximadamente, sua moeda em relação à moeda argentina tornando os produtos brasileiros mais competitivos ${ }^{8}$, a Argentina, pressionada pelo desemprego e pela recessão, aprovava medidas de proteção contra qualquer produto importado dos membros do Mercosul e, especificamente, um sistema de salvaguardas contra determinados produtos brasileiros, como têxteis, alegando que as regras do jogo haviam sido mudadas no meio da partida. Como não poderia deixar de ser, a situação de crise em ambos os países e conflitos comerciais entre eles, assim como as mudanças nas regras comerciais até então vigentes no Mercosul, atingiram os dois países menores, Uruguai e Paraguai, já fortemente integrados ao bloco, gerando atritos que levaram à paralisação da sua agenda negociadora e determinaram os fracos resultados do intercâmbio comercial entre seus membros.

No que se refere especificamente ao Uruguai, sua ligação histórica com a Argentina, seus $579 \mathrm{~km}$ de fronteira com esse país, seus onze anos de Mercosul e seus quatro de recessão fizeram da crise argentina um episódio de efeitos dramáticos. O Paraguai, por sua vez, que já vinha enfrentando um recrudescimento da pobreza e do desemprego, não conseguiu conter a desvalorização acentuada de sua moeda

7. Um fator significativo nas relações bilaterais Brasil-Argentina é que o Brasil é um parceiro comercial mais importante para a Argentina, do que esta para o Brasil. O volume de comércio argentino com o Brasil é maior do que com os Estados Unidos. No ano 2000, as exportações argentinas para o Brasil alcançaram 25,7\% e suas importações 27\%. Para os Estados Unidos, os números correspondentes foram de 11,3\% e 20,2\% (Saha, 2002).

8. Dado calculado pela Fundação Centro de Estudos de Comércio Exterior. 
e viu-se às voltas com uma crise institucional em que conflitos armados e ameaça de destituição do presidente Angel González Macchi, paralisaram economicamente o país (Brandão, 2002).

Examinando com mais detalhes a situação argentina, este país, que elegera para Presidente da República o candidato da Aliança, Fernando de la Rúa, em dezembro de 1999, se viu às voltas, após três anos de recessão, com uma crise de amplas proporções que trouxe novamente para o Ministério de Economia, em março de 2001, Domingo Cavallo que, durante o período presidencial anterior de Carlos Menem, implantara o sistema de paridade cambial entre o peso e o dólar, medida que arruinara grande parte da agricultura e da indústria argentina e favorecera a concentração oligopólica e a multiplicação geométrica de sua dívida externa (Meza, 2000).

Contudo, apesar das conseqüências negativas e das crí68 ticas que o prolongamento do modelo de câmbio fixo havia suscitado na opinião pública argentina, Domingo Cavallo retorna ao cargo revestido de poderes especiais, sendo recebido como o "homem destinado a salvar o país". Avaliava-se que, na falta de outra alternativa - de la Rúa já havia experimentado vários outros nomes para o posto - somente o ministro que fizera o país engolir a convertibilidade poderia reverter a crise em que a Argentina estava submergida (Meza, 2000).

Durante o período de governo de la Rúa/Cavallo, sucessivos planos de austeridade e medidas comerciais tomadas unilateralmente não conseguiram impedir o prolongamento da recessão. Estas últimas incluíam a redução a zero das tarifas de importação para bens de capital, peças e componentes e, paralelamente, o aumento das tarifas para a importação de bens de consumo final que, podendo chegar a $35 \%$, atingiam produtos comercializados dentro do Mercosul antes liberados. 
Logicamente, essas medidas justificavam os temores que haviam acompanhado o retorno de Domingo Cavallo ao Ministério de Economia relativos a um recuo do Mercosul a uma situação de Área de Livre Comércio, uma vez que o aumento das tarifas para bens de consumo dificultava a adesão dos países do bloco ao regime de Tarifa Externa Comum e ao funcionamento da União Aduaneira. Por outro lado, além de atingir o Mercosul, o Brasil se sentiu diretamente prejudicado pela generalização da tarifa zero para as importações de equipamentos e bens de capital, especificamente no que se refere a produtos de informática e telecomunicações. Pressões do governo brasileiro, contudo, conseguiram suavizar a medida, fazendo que o governo argentino retirasse do âmbito da tarifa zero os equipamentos na área das telecomunicações produzidos fora do bloco (Kumar Saha, 2002).

$\mathrm{Na}$ realidade, Domingo Cavallo, desde sua primeira gestão como ministro de Economia de Carlos Menem, sempre se mostrara contrário à implantação de uma União Aduaneira por considerar que tolhia suas decisões, impedindo-lhe de ter as mãos livres para implantar as medidas que julgasse necessárias. Por essa razão, se de um lado julgava importante preservar a continuidade do bloco, uma vez que esse acordo favorecia a abertura de mercados para os produtos argentinos, de outro, opunha-se a uma disciplina comercial comum que exigia de seus membros uma negociação conjunta, especialmente face à Alca e à União Européia (Vaz, 2002).

Abrindo um parênteses, gostaria de ressaltar que episódios como os que acabamos de descrever, de quase autismo por parte de governos que modificam unilateralmente as regras do jogo em que suas economias irão operar - especialmente em um contexto de países estruturalmente interdependentes e que desenvolvem projetos de integração de suas economias, como é o caso do Mercosul - dificultam o trajeto. Esses impasses mostram a necessi- 
dade de uma coordenação macroeconômica mais rígida entre os países do bloco e a adoção de decisões estratégicas comprometidas com algum grau de supranacionalidade, além de que põem em evidência a ambigüidade do discurso pró-Mercosul e a inconsistência de um enfoque efetivamente regional.

Fechando o parênteses e sem querer alongar-me na análise da crise argentina que crescia de intensidade sem que o Ministro Cavallo conseguisse debelá-la, queria assinalar que a forte divergência entre as políticas cambiais praticadas pelo Brasil e pela Argentina trazia em seu bojo a percepção do governo argentino de que era necessário investir em uma inserção internacional que associasse o país mais profundamente ao Ocidente, o que implicava, como estratégia básica, um forte alinhamento aos Estados Unidos. Nesse contexto o Brasil, apesar de seu peso e importância dentro do Mercosul, era visto pela Argentina como um país 70 que perturbava a ordem hemisférica, fazendo que a política de cooperação bilateral, condicionada à aceitação brasileira da hegemonia norte-americana na região, passasse para o terceiro lugar como objetivo da política externa argentina (Russel, 1995).

Em 20 de dezembro de 2001, no auge de uma crise de governabilidade e inadimplência que conduzira a Argentina à beira do caos econômico e social, o Presidente de la Rúa, depois de haver decretado estado de sítio no país, renunciava a seu mandato, gesto precedido pela renúncia de seu Ministro de Economia Domingo Cavallo. O cargo de Presidente da República seria então preenchido, por curtíssimos períodos, por quatro nomes, sendo finalmente designado pelo Congresso, em substituição ao Presidente em exercício Adolfo Rodriques Saá, e pelo período remanescente da administração anterior, ou seja, até meados de 2003, o Senador peronista Eduardio Duhalde. Uma das primeiras medidas de seu governo - orientado pelo Ministro de Eco- 
nomia Roberto Lavagna que assumira o cargo em abril de 2002 e que iria nele permanecer até meados de 2005 - foi romper com o regime de paridade fixa, vigente desde 1991, instrumento que constituía uma das áreas de maior divergência entre Argentina e Brasil. Com a mudança do sistema cambial na Argentina, abria-se caminho para novos entendimentos, apesar de que a instabilidade política do país e os conflitos comerciais, subproduto da crise econômica que permanecia sem solução, apontavam para uma intensa discussão sobre a funcionalidade e os rumos da integração ${ }^{9}$.

Em janeiro de 2003, é eleito para a presidência do país Nestor Kirchner, como resultado de um processo em que Carlos Menem, vitorioso no primeiro turno, abandona o pleito no meio do segundo, permitindo que o candidato derrotado fosse empossado no cargo com apenas $22 \%$ dos votos, em 25 de maio de 2003. Do ponto de vista do governo brasileiro, o novo presidente argentino foi considerado como um aliado natural e como parceiro privilegiado no âmbito do Mercosul, percepção também existente do lado argentino. Em seu discurso de posse, o Ministro de Relações Exteriores do Brasil, Celso Amorim, afirmava que o relacionamento com a Argentina "constituía o pilar da construção do Mercosul", acrescentando que, mesmo consciente das dificuldades da agenda econômico-comercial, o governo "enfrentaria com determinação as questões da Tarifa Externa Comum e da União Aduaneira, sem as quais a pretensão de negociar em conjunto com outros países e blocos seria mera ilusão" (Amorim, 2003).

Concretamente, nessa fase em que os problemas comerciais entre Argentina e Brasil atingiram níveis altos de con-

9. Em janeiro de 2002, o Congresso argentino aprovou a reforma da Lei de Convertibilidade, que deu ao Poder Executivo a faculdade de estabelecer o sistema que determinará a paridade entre o peso e as divisas estrangeiras e de ditar as regulações do câmbio. 
flito, o Itamaraty se mostrou receptivo aos protestos argentinos que reivindicavam, dada a assimetria econômica entre os países do Mercosul, medidas de proteção de seus setores menos competitivos. Reconhecendo que havia diferenças de tamanho entre as economias do bloco, a diplomacia brasileira se propôs a incorporar, em sua visão do Mercosul, a realidade da existência de assimetrias entre os membros do bloco $^{10}$. Nesse sentido abriu-se, no âmbito do Mercosul, por iniciativa do Ministro Roberto Lavagna, uma discussão sobre a adoção de um mecanismo que permitisse impor salvaguardas em caso de desequilíbrio entre as economias, como, por exemplo, quando houvesse desvalorização cambial em uma das partes ou protecionismo no caso de indústrias pouco competitivas ${ }^{11}$. Simultaneamente discutiu-se a necessidade de definir novas estratégias que incentivassem o desenvolvimento industrial dos dois lados da fronteira. Para o então Ministro Lavagna, o desenvolvimento do Mercosul depen72 dia essencialmente do investimento em infra-estrutura e da integração produtiva.

A discussão sobre salvaguardas vem de antes e se origina no fato de que as que estavam previstas no Tratado de

10. O Ministro de Relações Exteriores do Brasil, em declaração à imprensa, em 16 de dezembro de 2004, afirmou: "Nós precisamos tratar dos problemas que existem na relação Brasil-Argentina de uma maneira inteligente, que permita continuar avançando no processo de integração, reconhecendo que há assimetrias e que neste momento elas estão favorecendo mais o Brasil. Mas poderá haver momentos em que elas favoreçam à Argentina" (Portal Vermelho. Disponível em: <www.vermelho.org.br>. Acesso em: 5 jan. 2005).

11. O governo argentino apresentou ao Brasil, em setembro de 2004, duas propostas para a criação de um sistema permanente de cotas para importações que incluiam mecanismos para impedir eventuais invasões de produtos de países do Mercosul. Uma das medidas, que permite a um país impor cotas em caso de turbulências macroeconômicas nas relações comerciais, remete aos mecanismos de restrição impostos pelo governo de Carlos Menem logo após a desvalorização do real brasileiro, em 1999. A outra medida permite que um governo imponha cotas quando registrar aumento significativo nas importações de um determinado produto, independentemente da influência macroeconômica (ver Ariel Palácios, disponível em: <http//www.fiesp.com. br >). 
Assunção caducaram quando terminou, em dezembro de 1994, o período considerado de transição, sem que, contudo, as razões que haviam justificado sua inclusão no Tratado, deixassem de continuar presentes. A Argentina, em várias oportunidades, propôs que válvulas de escape fossem restabelecidas. Essa reivindicação se tornou mais forte em 1999, depois da desvalorização do Real, ocasião em que esse tema se recobriu de uma importância política significativa, sem que, no entanto, o Brasil tivesse concordado com a proposta. De lá para cá essa questão, diferentemente interpretada pelo Brasil e pela Argentina, tem ocupado o centro da agenda das relações comerciais entre os dois países, assim como o da agenda sub-regional. Do ponto de vista do Brasil, o cerne do argumento é que o problema argentino tem a ver com insuficiências estruturais de competividade em setores industrias do país, enfatizando que as salvaguardas, como medidas de proteção, são contrárias ao espírito e à letra do Tratado de Assunção. Para a Argentina, mesmo aceitando que as insuficiências existem, a questão se liga à falta de coordenação econômica que impede que se alcance a constituição de uma união aduaneira e em seguida a de um mercado comum.

Esses diferentes argumentos denotam que o conflito entre Brasil e Argentina, basicamente comercial e, que, há alguns anos, fora tratado pela Argentina com medidas unilaterais, destinadas a conter a chegada de determinados produtos brasileiros, como têxteis, calçados, geladeiras, máquinas de lavar e outros produtos, e por meio de cotas de ingresso, não se esgota em si mesmo. Termina por irradiar-se para outras esferas do Mercosul, gerando cepticismo e indefinição por parte dos próprios agentes do processo, no que se refere ao formato institucional ideal do bloco e à estratégia a ser seguida.

Com efeito, a percepção de alguns setores empresariais brasileiros de que o Mercosul perdera vitalidade produziu 
algumas teses favoráveis à idéia de que o processo de integração deveria desistir de caminhar na direção da formação de um mercado comum, ou mesmo de uma união aduaneira, e retroceder para uma zona de livre comércio. Ou ainda, como alternativa, que uma maior flexibilidade permitisse que o Mercosul caminhasse em duas velocidades, igualando-se, assim, a algumas propostas feitas no curso da formação da União Européia (Camargo, 1993).

No que se refere à primeira tese, a alternativa seria acabar com a Tarifa Externa Comum (TEC), proposta apresentada em fins de 2004 pelo diretor de Relações Internacionais e de Comércio Exterior da Federação das Indústrias de São Paulo (Fiesp), Roberto Gianetti da Fonseca, o que poderia abrir caminho para que os quatro sócios fundadores negociassem acordos comerciais de forma independente. Essa perspectiva, debatida dentro da sua entidade, contou com a simpatia de outras, como da Associação Brasileira de Expor-

74 tadores de Frangos (Abef) e da Associação Brasileira de Comércio Exterior (AEB). Esses setores, que enfrentavam problemas comerciais com a Argentina, atribuíam ao Mercosul o fracasso das negociações com a Europa e mesmo com a Alca. Para eles, não se tratava, contudo, de abandonar o Mercosul, mas de liberar o Brasil para negociar livremente com grandes mercados, como os Estados Unidos e a União Européia, sem que a âncora Mercosul lhes tolhesse os movimentos (Landim, 2004).

Uma segunda tese, apoiada em estudos dos economistas Fábio Giambiagi e Igor Baremboim e apresentada posteriormente pelo Instituto de Pesquisa Econômica Aplicada (Ipea), partia do princípio de que o Mercosul, sendo já uma realidade, acabara prejudicado por fragilidades que era necessário agora corrigir. Para isso, propunha a idéia de uma "arquitetura mais flexível", o que significava dividir o Mercosul entre, de um lado, o Brasil e a Argentina, que continuariam a pensar em avançar na consolidação de um 
mercado comum entre eles por um período que poderia estender-se até 2014 e que incluía a criação de uma moeda comum até 2017, e de outro, o Uruguai e o Paraguai, que se engajariam de forma mais limitada no processo. Essa proposta, que significava, na prática, um recuo até o Tratado de Buenos Aires de 1988, no qual se previa o mercado comum apenas entre Brasil e Argentina, restauraria a credibilidade interna e externa do bloco ${ }^{12}$.

Setores governamentais e do próprio empresariado brasileiro, contudo, liderados pelo Secretário Executivo da Câmara de Comércio Exterior, Mário Mugnaini, se opunham a essas alternativas. Consideravam que era necessário não retroceder no caminho percorrido - o que significaria uma "aladização" do Mercosul e uma mercantilização da questão - e sim fortalecer suas instituições, justamente como forma de viabilizar e administrar as relações bilaterais estabelecidas pelo bloco. No bojo dessa discussão, o setor privado brasileiro pareceu, finalmente, chegar a um acordo com os empresários argentinos: o Brasil obteria a garantia, com validade até dezembro de 2005, de que poderia participar em $50 \%$ no mercado argentino de certos produtos, como os eletrodomésticos, comprometendo-se a Argentina a não solicitar medidas adicionais de proteção durante a vigência do pacto. Contudo, posteriormente, as negociações entre fabricantes brasileiros e argentinos se deterioraram, tendo a participação do Brasil no mercado vizinho sido fixada em não mais do que $35 \%$, garantindo-se a de outros países fornecedores $11 \%$. Os outros $54 \%$ seriam garantidos a fabricantes locais ${ }^{13}$.

12. Ver: Global 21, 5 de dezembro de 2005. Disponível em: <http://www.global 21.com.br $/$ materias $/$ materia asp?tipo $=$ noticia\&cod $=9660>$.

13. Segundo o então Ministro de Economia argentino, Roberto Lavagna, $95 \%$ das importações de geladeiras da Argentina se concentram no Brasil, assim como 70\% das máquinas de lavar e $100 \%$ dos fogões (Folha de S.Paulo, 3 dez. 2004). 
Essa discussão foi retomada na Cúpula do Mercosul, realizada em Montevidéu, em novembro de 2005, ocasião em que a Argentina e Brasil chegaram a um acordo a respeito da adoção de um Mecanismo de Adaptação Competitiva (MAC) que agiria como salvaguarda, isto é, como um instrumento que regularia o comércio e serviria de proteção a determinados setores sensíveis se um surto de exportações de um outro país os estivessem prejudicando. Esse mecanismo de proteção, sendo temporário, veio acompanhado de requisitos para que pudesse ser prorrogado, determinando que o país que o solicitasse cumprisse determinadas metas, como investimento, produtividade e outras, que lhe permitiriam recuperar seu parque industrial.

A aceitação dessa cláusula, contudo, está longe de ser unânime por diferentes motivos. De um lado estão as queixas do Uruguai e do Paraguai que se sentiram excluídos de negociações nas quais se consideravam atores importan76 tes. No caso do Uruguai, esta posição caminha paralela ao projeto de negociar um Tratado de Livre Comércio com os Estados Unidos por avaliar mais vantajoso para a economia do país consolidar sua posição comercial com uma grande potência que é, ao mesmo tempo, o principal mercado para suas exportações. Apesar disso, afirma seu compromisso com o Mercosul, caso a tese das duas velocidades não tenha prosseguimento. No que se refere ao Paraguai, que já solicitou uma reunião de chanceleres do Mercosul no prazo mais curto possível, o governo alega que o país deveria ter participado das negociações, uma vez que já apresentara anteriormente uma proposta de incorporação de salvaguardas que deveria ser estendida a todos os países do bloco. $\mathrm{Na}$ visão dos principais negociadores paraguaios, o que pretendem fazer é examinar em detalhe o acordo fechado entre Brasil e Argentina para depois tomar posição, querendo com isso resgatar a imagem negativa do Mercosul perante a sociedade paraguaia. 
Ao lado das críticas dos dois menores países do Mercosul colocam-se, mais uma vez, setores empresariais brasileiros que apontam as salvaguardas como mais um retrocesso do projeto de integração. Entre eles a CNI (Confederação Nacional da Indústria) e a Fiesp (Federação das Indústrias de São Paulo) que consideram que, com o acordo recémfechado pelo Brasil e Argentina, se volta à situação anterior ao Tratado de Ouro Preto de 1994 que eliminara as barreiras tarifárias e criara a Tarifa Externa Comum (TEC). Argumentam que, havendo sido originalmente contrários ao estabelecimento de medidas de salvaguarda, terminaram por defender junto ao governo brasileiro condições mínimas para preservar as indústrias nacionais. Mas mesmo estas condições não haviam sido cumpridas.

Paralelamente ao tema das salvaguardas, o acordo automotivo entre Brasil e Argentina é outra questão que agita o Mercosul. O acordo até aqui vigente, que se iniciara em 2001 e que deveria terminar em 1. ${ }^{\circ}$ de janeiro de 2006, data em que o livre comércio automotivo começaria a funcionar, foi prorrogado para $1 .^{\circ}$ de julho do ano em curso, quando um novo acordo entraria em vigor. Um dos principais pontos do acordo de 2001 é a constituição de um mecanismo de compensação das exportações - $o$ trade flex - por meio do qual se prevê que, a partir do volume de exportações efetivamente realizadas, se aplica um flex, isto é, um número que define o limite das importações sem pagamento de impostos de importação. Os benefícios trazidos por esse instrumento, na medida em que estão ligados à conjuntura econômica de cada país, tanto podem favorecer um como outro país. Em 2001, por exemplo, quando o instrumento começou a vigorar, a Argentina, cuja crise a tornava incapaz de absorver sua produção automotiva, passou a exportar ao Brasil além do limite permitido, gerando no Brasil importações tributadas, situação que posteriormente se inverteu em benefí- 
cio do Brasil. Atualmente, $63 \%$ dos automóveis vendidos na Argentina são fabricados no Brasil. Em contrapartida, 2,8\% dos veículos vendidos no Brasil são importados do país vizinho ${ }^{14}$.

Às diferentes questões até aqui examinadas e que se relacionam com a importância e extensão do Mercosul que nós conhecemos, se acrescentam outras que têm a ver com a ampliação do bloco, não apenas no que se refere à entrada de novos sócios, Bolívia, Chile, Peru, México, mas de candidatos à adesão como membros plenos, como no caso já concretizado da Venezuela. Não pretendo examiná-las aqui nem prever as que poderiam surgir, o que implicaria muitas páginas a mais. Quero apenas registrar que a proposta de formação de uma Comunidade de Nações Sul-Americanas, projeto que está na agenda do governo brasileiro e de alguns outros do nosso subcontinente, vai exigir, como ponto de partida, uma consolidação e um aprofundamento 78 do Mercosul.

\section{0 debate institucional}

Como ficou claro até aqui, a discussão sobre as relações comerciais no Mercosul foi o tema predominante em todo seu trajeto, em contraste com a questão institucional, propositadamente negligenciada pelos próprios Estados-membros por considerarem que poderia trazer uma burocratização excessiva ao processo ou uma perda de soberania dos Estados - ou mais, perda de poder, no caso brasileiro - sem que, necessariamente, os problemas fossem resolvidos. Contudo, o próprio fato de que estes últimos anos tenham sido sacudidos por uma escalada de conflitos comerciais e pelo retardamento dos avanços no caminho da formação de um mercado comum mostrou que o aprofundamento do debate e das decisões político-institucionais não podia ser adiado.

14. Informações do Ministério de Desenvolvimento, Indústria e Comércio Exterior. 
A idéia inicial foi então aproveitar a revisão do Protocolo de Ouro Preto, prevista para ocorrer no âmbito da Cúpula do Mercosul, em dezembro de 2004, em Belo Horizonte, para fazer um repasse de todo o Mercosul, ocasião em que se definiriam alguns aspectos de sua estrutura institucional, desatualizada em alguns casos e, em outros, carentes de novos instrumentos que dessem ao processo novo impulso e legitimidade. Esse documento que, em sua primeira versão, em fins de 1994, produzira inovações positivas relativas à definição de regras referentes à Tarifa Externa Comum (TEC) aos produtos sensíveis e aos setores automotivo e açucareiro e à criação de novos organismos foi, contudo, pouco aproveitado. Em uma segunda versão, pretendeu-se discutir questões referentes à elaboração de novos mecanismos para a tomada de decisões e medidas que favorecessem um maior desenvolvimento do mercado ampliado e neutralizassem as distorções nas políticas macroeconômicas do bloco, o que deveria assegurar a convergência estrutural entre os Estados-membros e o aprofundamento de sua integração produtiva Os resultados foram, igualmente, pouco eficazes (Raimondo, 2004).

Antes de examinar os principais pontos que foram discutidos na Cúpula de Belo Horizonte, acima referida, e os resultados obtidos, gostaria de colocar algumas questões que poderiam ajudar a avançar na reflexão sobre o processo de revisão do Mercosul. Uma delas é bastante clara: a de que a funcionalidade do bloco tem sido praticamente avaliada apenas pelos seus resultados comerciais, considerados positivos, apesar dos conflitos que têm gerado. Já em termos econômicos gerais, sua integração produtiva é vista como limitada, ou mesmo inexistente, e seu avanço na direção da formação de um mercado comum apoiado em instituições comunitárias fortes, praticamente abortado. Esse tipo de avaliação justifica a posição de alguns setores empresariais, como já foi assinalado, que defendem a volta a uma área de 
livre comércio, o que permitiria ao Mercosul obter resultados mais seguros e prazos mais curtos.

Contudo, outras dimensões deveriam ser levadas em conta, ainda que seus resultados tenham sido, até agora, pouco consistentes. Caberia pensar que a funcionalidade do Mercosul estaria ligada a uma melhor forma de regular e administrar, em benefício de seus Estados-membros e de suas sociedades, o movimento global de transnacionalização financeira e de abertura dos mercados. Ou, em outras palavras, a uma maior coordenação macroeconômica que agisse como um instrumento para a construção de um ator unificado em torno de objetivos políticos comuns, com mais força de negociação nas instituições multilaterias e nas relações internacionais em geral. A posição conjunta dos Estados-membros do Mercosul referente a esses temas e a outros, como a necessidade de uma maior integração produtiva e de mudança em sua estrutura institucional, 80 assim como de resistência às pressões vindas de Estados ou regiões mais fortes que desejassem incorporá-los, individualmente, a suas áreas de influência e poder, pode significar um meio de fortalecer uma identidade regional própria e uma imagem internacional com contornos mais definidos.

A discussão sobre mudanças nas instituições do Mercosul tem gerado, porém, resistências no âmbito de certos setores governamentais, especialmente nos meios diplomáticos brasileiros, tendência que parece haver-se enfraquecido. Os argumentos tradicionalmente contrários a uma maior rigidez - além daquele que se refere à perda de soberania institucional já apontada anteriormente - se apóiam na preocupação de que uma excessiva burocratização do processo possa conduzir a seu fracasso, como aconteceu, segundo se alega, com os esquemas de integração dos anos 1960, ou ainda, na avaliação de que o modelo institucional vigente, o de uma união adu- 
aneira imperfeita, é bastante adequado à atual fase vivida pelo Mercosul ${ }^{15}$.

Ambos os argumentos me parecem discutíveis. No que se refere ao primeiro, o fracasso relativo dos esquemas anteriores de integração na América Latina teve várias causas além de sua alegada burocratização, mesmo que esta tenha existido. Suas razões podem estar ligadas não ao excesso de regras e normas, e sim à reduzida participação dos empresários no processo e a dos trabalhadores organizados, praticamente inexistente. Quanto ao segundo, é justamente a falta de regras e instituições que dificulta o funcionamento de uma Tarifa Externa Comum (TEC), impedindo com isso a implementação de uma União Aduaneira efetiva. No que se refere ao argumento da perda de soberania, esta se liga, na conjuntura atual do Mercosul, não a um possível avanço na construção de instituições com algum grau de supranacionalidade, mas à forma pela qual as empresas transnacionais, que agem livremente nos mercados globais, atropelam projetos e decisões formuladas no âmbito dos Estados e das regiões em processo de integração. Contudo, isso não invalida o fato de que o estabelecimento de um mercado comum traz consigo cessão de soberania, ainda que seja parcial, o que não é necessariamente um fator negativo em um contexto de países que pretendem cooperar politicamente e se integrar economicamente.

Na realidade, não há como escapar ao fato de que a passagem de mercados nacionais para um mercado único regional modifica a qualidade das relações entre os Estados-membros e entre suas sociedades, assim como o peso dos diferentes agentes produtivos e a localização de suas atividades. Essas alterações e deslocamentos trazem mudan-

15. Essa caracterização se refere ao fato de que a Tarifa Externa Comum (TEC) está sendo concretamente aplicada para $85 \%$ dos produtos. Os $15 \%$ restantes estão em lista de exceção nacional ou nas listas de convergência, sujeitos a regras específicas e cujas tarifas variam de $20 \%$ a $35 \%$ até o ano 2006. 
ças nas regras do jogo político entre os atores nacionais e os que já atuam nos planos regional e global, o que exige uma contínua revisão dos instrumentos de decisão, regulação e representação de que podem dispor, podendo ser intergovernamentais ou supranacionais, de acordo com o objetivo final que se quer alcançar e de sua eficácia e operacionalidade para realizá-lo. Nesse sentido, o modelo da União Européia, ao combinar órgãos intergovernamentais e supranacionais que se comunicam entre si por meio de diferentes esquemas e procedimentos, dentre os quais os ligados ao princípio da subsidiariedade, é um bom exemplo de solução pragmática e exeqüível (Camargo, 1993).

Retomando a questão da revisão do Protocolo de Ouro Preto, o clima que antecedeu a XXVII Reunião do Conselho do Mercado Comum fazia prever que seria difícil chegar a um consenso sobre grande parte das propostas. Com efeito, em diversos encontros de técnicos realiza82 dos nos dias anterior, o impasse entre Brasil e Argentina relativo à implantação de mecanismos que protegessem os setores menos competitivos, as tão discutidas salvaguardas defendidas pelo Ministro Roberto Lavagna, não parecia alcançar uma solução satisfatória, dada a irredutibilidade das duas partes ${ }^{16}$. Diante desse quadro, a percepção mais generalizada no meio empresarial era de que as perspectivas para o encontro em Belo Horizonte e Ouro Preto não eram nada animadoras, presumindo-se que a reunião iria avançar mais nos aspectos simbólicos e retóricos do que naqueles ligados, concretamente, às reivindicações do setor privado.

16. A reivindicação do governo e empresários argentinos apóia-se no fato de que a indústria brasileira é 4,9 vezes maior do que a da Argentina. O setor de máquinas e equipamentos elétricos no Brasil supera o país vizinho em 17 vezes e a área de máquinas e equipamentos que incluem a linha branca é 6 vezes maior no Brasil. (Dados do Centro de Estudos Bonaerenses - CEB, reproduzidos pelo Estado de $S$. Paulo, 4 dez. 2004). 
Se, em grande parte, isso assim se deu, a atitude dos diplomatas brasileiros, ao contrário da dos empresários, foi a de minimizar as dificuldades, afirmando que o Mercosul estava acima de uma mera disputa comercial bilateral, mostrando-se sensíveis, em princípio, à demanda argentina de instituir instrumentos de proteção. Contudo, na sua avaliação, o importante era negociar incansavelmente até encontrar uma solução melhor do que as medidas unilaterais adotadas sem critérios e sem prazo definidos (Landim, 2004). Como primeiro passo, os negociadores dos países do Mercosul chegaram a um consenso prévio de que, como forma de não contaminar o encontro, o tema não seria tratado no âmbito da Cúpula, e sim discutido bilateralmente entre os governos do Brasil e da Argentina, e só depois levado às instâncias do Mercosul.

Dessa maneira, a partir do pressuposto de que "a solução dos problemas do Mercosul deveriam ser buscadas em mais Mercosul”, segundo as palavras do Ministro Celso Amorim (2003) a Cúpula de Ouro Preto, em lugar de retroceder, abrindo mão do objetivo de constituir um mercado comum, como anteviam alguns setores empresariais, fez uma aposta para o futuro. Nesse sentido, medidas importantes foram tomadas, ainda que não sujeitas a uma implantação imediata, como a criação um Fundo de Convergência Estrutural, previsto para ser implantado no curso de 2006, destinado a aparar as arestas das assimetrias e diminuir as desigualdades na região, cujo valor total e cota de participação de cada Estado seriam indicados por decisão consensual entre eles. Decidiu-se ainda avançar em diferentes temas, como na harmonização de trâmites jurídicos e regras de controle de mercadorias para facilitar os negócios e as trocas comerciais e assinou-se um acordo referente a compras governamentais para permitir que empresas de um país do Mercosul pudessem participar de licitações federais em qualquer um dos outros países-mem- 
bros. Paralelamente, em termos de ampliação geográfica, Colômbia, Equador e Venezuela juntaram-se à Bolívia, que já fora incorporada ao bloco como membro associado, devendo assim aderir à cláusula democrática do Mercosul (Freire Neto, 2004). Em dezembro de 2005, na Cúpula de Buenos Aires, a Venezuela deu mais um passo à frente, na medida em que saiu do encontro como "um membro em via de adesão”, o que situa o país em primeiro lugar na corrida para membro pleno do Mercosul.

Outras medidas, contudo, ficaram de fora. Dentre elas, a revisão da Tarifa Externa Comum (TEC), que, acumulando hoje mais de 800 perfurações, tem impedido que a União Aduaneira se torne um instrumento efetivo de integração. Da mesma maneira, não houve avanço na revisão do Protocolo de Ouro Preto no que se refere ao processo decisório, no sentido de terminar com a exigência de consenso, alegando-se que sua extinção criaria uma nova frente 84 de conflito com Argentina, uma vez que Paraguai e Uruguai declararam apoiar o Brasil contra as medidas de salvaguardas propostas pelos argentinos.

Um tema importante discutido na Cúpula de Ouro Preto foi a criação do Parlamento do Mercosul, que deveria ser implantado em fins de 2006 e cujas regras seriam definidas pela Comissão Parlamentar Conjunta. Esta iniciativa, retomada em novembro de 2005 em Buenos Aires na ocasião em que a Comissão Parlamentar se reuniu para examinar o Protocolo Constitutivo do Parlasur, decidiu que sua implantação se daria de $1 .^{\circ}$ de janeiro de 2007 a 31 de dezembro de 2014 e que, nos primeiros cinco anos, os parlamentares seriam designados pelas instâncias legislativas nacionais, passando depois a serem eleitos por sufrágio universal. No que se refere à representatividade por país, a decisão final, depois de uma proposta em que a Comissão Parlamentar Conjunta defendia a representação segundo critérios não paritários - Brasil com 36 representantes, Argentina 
com 31 e o Uruguai e Paraguai com 16 - foi de que cada Estado-membro contará, até 2011, com 18 representantes, Somente depois desse período, o Parlamento poderá adotar o princípio da proporcionalidade representativa, segundo a população de cada país.

Cabe assinalar, porém, que a implantação dessas e de outras medidas dependerá de questões internas de cada país-membro e de seu reflexo sobre as relações entre eles. Há uma grande quantidade de decisões a serem aprovadas nos parlamentos de cada um dos países do bloco e outras, igualmente numerosas, que esperam, simplesmente, para serem executadas. A capacidade de coordenação política do Mercosul é frágil. A criação do Parlasur, ao produzir normas comunitárias, vai, exatamente, dotar o Mercosul de maior legitimidade e consistência democrática, apesar de ser um tema polêmico, uma vez que implica, como já foi assinalado, cessão de soberania.

Quero lembrar que, para que normas comunitárias possam ser efetivamente adotadas no Mercosul, é necessário que elas sejam previamente incorporadas aos ordenamentos jurídicos de cada um de seus Estados-membros. Sem querer abrir uma discussão técnico-jurídica sobre esse ponto, não se pode deixar de lado o fato de que, sem que seja criada uma estrutura própria que garanta aos agentes econômicos do bloco e ao seu conjunto de cidadãos segurança e previsibilidade em sua inserção com os demais parceiros, os impactos negativos sobre os resultados do processo de integração serão inevitáveis (Keger, 2005).

O procedimento de incorporação definido no art. 40 do Protocolo de Ouro Preto é mais complexo do que o habitual para os Tratados em geral. Segundo esse documento, o procedimento em sua primeira etapa é similar ao previsto constitucionalmente em cada um dos Estados-partes para qualquer norma do Direito Internacional. Mas, uma vez editada a norma, passa-se a uma segunda etapa, a de 
informar à Secretaria do Mercosul o ato de incorporação e, posteriormente, a de aguardar que esse órgão comunique a informação aos demais Estados. Em um prazo de trinta dias depois dessa notificação, e tendo cada Estado já oficializado individualmente o ato por meio de sua publicação no Diário Oficial, dá-se início à vigência da norma.

Nem sempre, porém, as coisas ocorrem dessa maneira. Em alguns casos o Conselho do Mercado Comum deixa de utilizar, em suas decisões, o mecanismo de incorporação previsto no Protocolo de Ouro Preto. Isso se deve ao fato de que, no caso do Mercosul, a possibilidade do Tratado de Assunção de editar normas de caráter obrigatório emanadas de órgãos decisórios/jurisdicionais do bloco regional, como ocorreu com o Tratado de Roma, na Comunidade Européia, é ainda matéria de discussão entre lideranças políticas e juristas (Keger, 2005).

Na realidade, a controvérsia sobre o papel do Tratado 86 de Assunção como elemento ordenador de uma estrutura jurídica independente e autônoma traz à tona as inconsistências entre um discurso que se propõe a unificar politicamente a sub-região e uma prática que favorece o conflito e a contradição. Por outro lado, além de o art. 42 do Protocolo de Ouro Preto especificar que a incorporação de normas aos ordenamentos jurídicos nacionais se faça "quando necessária", o que enfraquece a possibilidade de uma ação simultânea e uniforme do conjunto de seus membros, existe o fato de que as normas a serem incorporadas são de dois tipos, o que torna mais complexo o processo: umas, por sua natureza, exigem a co-participação do Poder Legislativo; outras, de natureza puramente regulamentar, exigem a participação do Poder Executivo, que, por meio de portarias e decretos, as introduzem na ordem jurídica nacional (Keger, 2005).

A situação acima descrita mostra a dificuldade em se constituir uma base jurídica para o funcionamento do Mer- 
cosul. Mesmo que muitos acreditem que o processo de integração sub-regional, que, minimamente, já se constituiu como uma União Aduaneira, possa avançar comercialmente sem a criação de instrumentos especificamente comunitários, dificilmente o bloco poderá alcançar segurança jurídica e previsibilidade política para a livre circulação de pessoas, bens e fatores produtivos, base para a formação de um mercado comum e para a atração de investimentos que acelerem o crescimento da região.

\section{Conclusão}

Para encerrar em poucas linhas este trabalho, quero apenas destacar que o Mercosul tem diante de si desafios pesados em três arenas separadas - Mercosul/EU, Alca e OMC - negociações que, vistas como um processo único em tabuleiros distintos, incluem, como prioridade, acesso dos produtos de seus países a mercados centrais fortemente protegidos ou pouco explorados (Veiga, 2002).

Essa questão adquire maior importância na conjuntura atual da América do Sul, em um momento em que a perspectiva de uma integração de todo o sub-continente, na forma de uma Comunidade Sul-Americana de Nações, começa a fazer parte da agenda de seus países, segundo a Declaração de Cuzco, assinada em fins de dezembro de $2004^{17}$. Para que isso ocorra, isto é, para que os quatro países do Mercosul, os cinco da Comunidade Andina de Nações, mais o Chile, o Suriname e a Guiana se integrem, o prazo previsto é não menos do que quinze a vinte anos, período durante o qual o Mercosul agiria como uma plataforma política nas negociações birregionais e multilaterais.

Para dar realidade a esse projeto, que se propõe a ser o programa mais ambicioso da região e, possivelmente, o mais utópico, pretende-se dar prioridade, nos próximos cin- 
co anos, aos setores de infra-estrutura, transporte, energia e comunicações, visando com isso à integração física do subcontinente, na tentativa de atrair apoio dos demais países da região para as propostas defendidas pelo Brasil e pelo Mercosul nas grandes negociações internacionais ${ }^{18}$. O consenso em torno dessa iniciativa tem como suporte três pilares básicos: integração de sua infra-estrutura física, convergência entre o Mercosul e a Comunidade Andina e definição de políticas comuns em face de organismos multilaterais.

São essas as tarefas e responsabilidades que, na área externa, os países da América do Sul/Mercosul têm pela frente a curto, médio e longo prazo caso efetivamente se proponham, como o fazem seus interlocutores do Norte, a defenderem seus interesses nacionais, sub-regionais e regionais em todas as arenas em que suas prioridades são negociadas. Não há como chegar a isso isoladamente, uma vez que a assimetria entre os dois hemisférios, o do norte e o 88 do sul, e suas diferentes inserções no cenário mundial, dificultam o estabelecimento de acordos que signifiquem um avanço real para as nações sul-americanas em seu projeto de desenvolvimento econômico e social.

Contudo, cabe lembrar que, para que tudo isso não passe de uma mera retórica dos governos da região, ou mesmo de uma utopia a longo prazo de suas sociedades, o Mercosul, que representa o embrião de uma possível integração sul-americana, terá que solucionar seus problemas internos para impedir que os conflitos que surjam em seu âmbito não congelem sua agenda - como tem ocorrido entre Brasil e Argentina, e que certamente ocorrerá, em maior profusão e diversidade, com a ampliação do número de seus Estados-membros - e que atritos comerciais mal

18. Estas informações foram apresentadas no Correio Sindical Latino-Lamericano, n. 0 , primeira quinzena de 2005 . 
resolvidos e posições políticas tomadas unilateralmente, produzam desgastes do próprio bloco, com a decorrente percepção de que este está em sua fase terminal.

\section{Sonia de Camargo}

é professora associada e pesquisadora do Instituto de Relações Internacionais da Pontifícia Universidade Católica do Rio de Janeiro (PUC-RJ)

\section{Referências bibliográficas}

AMORIM, Celso. 2003. "Inserção global do Brasil: OMC, Mercosul, ALCA, Zona de Livre Comércio do Brasil com a União Européia”. XV Palestra no Forum Nacional, Rio de Janeiro: BNDES. 21 de maio.

. 2004. "De Ouro Preto a Ouro Preto". Jornal da Ciência, 29

de dezembro. Disponível em: <http://www.sbpcnet.org.br/>.

BATISTA JUNIOR, Paulo Nogueira. 2005. "Brasil, Argentina e América do Sul”. Estudos Avançados. São Paulo, vol. 19, n. 55, set./dec.

BERNAL-MEZA, Raúl. 2000. Sistema Mundial y Mercosur. Globalización, Regionalismo y Políticas Externas Comparadas. Buenos Aires: Universidad Nacional del Centro de Províncias de Buenos Aires/Grupo Editor Latinoamericano.

BRANDÃO, Vladimir. 2002. "Mercosul Contagiado”. Época, edição 212, 10 de junho.

CAMARGO, Sonia; VÁSQUEZ OCAMPO, José Maria. 1988. Autoritarismo e democracia na Argentina e Brasil (uma década de política exterior - 1973-1984). São Paulo: Editora Convívio.

CAMARGO, Sonia. 1989. "Brasil e Argentina, a integração em questão". Contexto Internacional. Rio de Janeiro, n. 9, ano 5, jan./jun.

. 1993. "Europa Ocidental e América do Sul: duas regiões à procura de sua integração". Contexto Internacional, Rio de Janeiro, vol 15, n. 2 , jul./dez.

. 2002. "Área de Livre Comércio das Américas: o labirinto latino-americano”. In: GOMEZ, J. M. (org.). América Latina y el (des)ordem global neoliberal: hegemonia, contra-hegemonia, perspectivas. Buenos Aires: Consejo Latinoamericano de Ciências Sociales.

CASTRO, Antonio Barros; SOUZA, Francisco Eduardo Pires. 1985. A Economia Brasileira em Marcha Forçada. Rio de Janeiro: Paz e Terra. 
FURTADO, Celso. 1982. A nova dependência: dívida externa e monetarismo. Rio de Janeiro: Paz e Terra.

GIAMBIAGI, Fabio; BAREMBOIM, Igor. 2005. "Mercosul: por uma nova estratégia brasileira”. Revista do BNDS, Rio de Janeiro, vol. 12, n. 24, dezembro.

KEGER, Patricia Luiza. 2005. "Aspectos jurídicos e institucionais do Mercosul: pontos para a discussão" Debate Mercosul, Rio de Janeiro: Centro Brasileiro de Relações Internacionais (CEBRI), abr./jun.

KUMAR SAHA, Suranjit. 2002. Relações bilaterais Brasil-Argentina no contexto do Mercosul e da Alca: um estudo do manejo das assimetrias. Palestra proferida na Universidade Federal de Pernambuco (UFPE), 12 de setembro.

LANDIM, Raquel. 2004. "Diretor da Fiesp propõe que o Mercosul dê um passo atrás”. Valor Econômico, 12 de novembro. Disponível em: <http: // clipping.planejamento.gov.br>.

LAVAGNA, Roberto. 1995. "Alianzas regionales: Mercosur, Nafta y la Unión Latinioamericana”. Argentina y Brasil en el Mercosur. Grupo Editor Latinoamericano.

MEDEIR0S, Marcelo. 2000. La genèse du Mercosul. Paris: L'Harmattan.

RUSSEL, Roberto. 1995. "Políticas exteriores: hacia una Política Común". In: RAPOPORT, M. (org.). Argentina y Brasil en el Mercosur: politicas comunes y alianzas regionales. Buenos Aires: Grupo Editor Latinoamericano.

TEIXEIRA, Alexandre. 2006. "A integração produtiva no Mercosul”. Correio Sindical, n. 20 e 22 de janeiro a 12 de fevereiro.

VAZ, Alcides Costa. 2002. Cooperação, integração e processo negociador: a construção do Mercosul. Brasília: Editora Instituto Brasileiro de Relações Internacionais.

VEIGA, Pedro da Motta. 2002. Na integration approachto the European Union/ Mercosur Association. Ed. P. Giordano. Paris: Chaire Mercosur de Sciences Sociales. 


\section{MERCOSUL: CRISE DE CRESCIMENTO OU CRISE TERMINAL?}

SONIA DE CAMARGO

$\mathrm{O}$ artigo examina a presente situação do Mercosul levando em conta as principais dificuldades que obstaculizam sua consolidação e seu avanço. Para tanto, reconstitui os conflitos comerciais que separam os dois maiores países do bloco, Brasil e Argentina, em um contexto em que as recentes crises econômicas internas de seus Estados-membros e a fragilidade dos mecanismos institucionais comunitários intensificam os obstáculos para avançar no processo de integração. O ponto de partida da análise é que o Mercosul está em crise, o que gera diferentes posições por parte de seus agentes, entre os quais, de um lado, setores do empresariado brasileiro, que põem em questão a pertinência de se prosseguir em um caminho que julgam pouco funcional, e de outro, outros setores empresariais e, especialmente, alguns governos da região que defendem seu aprofundamento e ampliação. $\mathrm{O}$ artigo propõe-se a reconstituir esse debate que abre caminho para uma discussão sobre a estrutura institucional do Mercosul, dimensão que assegura a previsibilidade das suas ações e práticas e a possibilidade de sua realização, condição para o desenvolvimento do bloco e de seus Estados-membros.

Palavras-chave: Mercosul; Mecanismos de proteção; Instituições Comunitárias; Integração.

\section{MERCOSUL: A PASSING CRISIS OR A TERIMINAL ONE?}

This article analyses the present situation of Mercosul, considering the main difficulties that paralyses its consolidation 
and advancement. The approach will look into the conflicts that separate its two biggest countries, Brazil and Argentina, in a context where the recent economic domestic crisis of its member States and the fragility of its institutional structure deepen the challenges to get ahead with the integration process. The starting point of the analysis is that the Mercosul is in crisis, a perception that generates different positions among its agents. On one side, there are business sectors that question the viability to follow a road which in their opinion is close and, on the other side, business sectors and specially some governments of the region that defend its consolidation and enlargement. This article reconstructs that debate, which opens the discussion about the institutional structure of Mercosul that ensures the forecast of its actions and practices and about the possibility of its achievement, and so stearing the development of the region and its member States.

Keywords: Mercosul; Protection Mechanisms; Communitary Institutions; Integration Process. 